\title{
REPRESENTASI VISUAL MATEMATIS MAHASISWA DALAM MEMODELKAN KEJADIAN DINAMIS DITINJAU DARI PERBEDAAN GAYA KOGNITIF DAN JENIS KELAMIN
}

\author{
Ulumul Umah $^{1 *}$, Ciptianingsari Ayu Vitantri ${ }^{2)}$ \\ ${ }^{1,2)}$ Pendidikan Matematika, FKIP, Universitas Pesantren Tinggi Darul Ulum, Kompleks \\ PP.Darul Ulum Peterongan Jombang, 61481 \\ *ulumul.ummah@gmail.com
}

\begin{abstract}
Abstrak
Representasi matematis memiliki peran penting dalam proses pemahaman konsep, penyampaian gagasan, mengoneksikan antar ide matematis, serta memodelkan masalah situasi nyata. Masalah situasi nyata yang melibatkan penyelesaian matematis antara lain berupa masalah yang berkaitan dengan kejadian dinamis yaitu perubahan nilai-nilai pada variabel seperti kecepatan dan laju. Penelitian terdahulu menunjukkan bahwa ada kecenderungan perbedaan cara belajar antar individu dengan gaya kognitif field dependent dan field independent. Selain itu, juga ditemukan perbedaan performa akademik antara lakilaki dan perempuan, meskipun tidak semua penelitian menunjukkan adanya perbedaan yang signifikan. Artikel ini mendeskripsikan bentuk representasi visual yang ditunjukkan oleh masing-masing subjek ketika memodelkan suatu kejadian dinamis terkait dengan perubahan nilai-nilai variabel. Analisis data penelitian dilakukan melalui metode kualitatif. Subjek penelitian terdiri dari empat mahasiswa dengan kombinasi gaya kognitif dan jenis kelamin yang berbeda. Hasil penelitian menunjukkan bahwa subjek laki-laki dengan gaya field independent memiliki kecenderungan lebih kuat untuk menggunakan bantuan representasi nonkonvensional sebelum menyatakannya dalam representasi yang lebih konvensional berupa grafik.
\end{abstract}

Kata Kunci: representasi visual, gaya kognitif, model kejadian dinamis .

\section{PENDAHULUAN}

Kesadaran tentang proses kejadian dinamis telah dibuktikan oleh para peneliti sebagai landasan penting bagi siswa untuk berpikir pada konsep-konsep kalkulus lebih lanjut. Transformasi konsep kalkulus sekitar abad 19 membuahkan kecanggihan bagi matematikawan untuk menyelesaikan berbagai masalah matematis, namun di sisi lain hasil transformasi ini juga meninggalkan tantangan kognitif yang besar bagi siswa sebagai pemula (Tall, 2009). Transformasi tersebut terjadi melalui perubahan dari konsep-konsep dinamis 
yang berkaitan dengan perubahan nilai menjadi konsep yang berdasarkan definisi formal limit epsilon-delta. Para peneliti sepakat bahwa walaupun definisi berdasarkan pandangan lama telah bertransformasi menjadi definisi formal saat ini, namun siswa masih perlu memiliki pengalaman tersebut sebelum melangkah pada definisi formal yang telah disepakati (Thompson \& Carlson, 2017; Tall, 2009).

Sejalan dengan konsep dinamis dalam kalkulus, maka diperlukan kemampuan siswa dalam memodelkan kejadian dinamis secara visual. Pengalaman dalam memodelkan situasi dinamis ke dalam model visual grafik akan berperan dalam pemahaman intutif terhadap konsep-konsep kalkulus seperti limit dan turunan. Pengalaman ini terkait dengan proses penalaran kovariasional pada saat mengonstruk grafik fungsi (Carlson, Jacobs, Coe, Larsen, \& Hsu, 2002). Namun, di samping representasi formal atau konvensional seperti grafik, dimungkinkan adanya peran representasi nonkonvensional dalam proses pembelajaran. Arcavi (2003) mengungkapkan bahwa visualisasi tidak lagi hanya berfungsi sebagai ilustrasi saja, namun juga menjadi komponen kunci dalam penalaran.

Representasi merupakan salah satu kemampuan matematis yang harus dikuasai siswa. NCTM (2002) menyarankan standar agar siswa memiliki kemampuan representasi untuk memodelkan dan mengintrepretasikan fenomena fisik, sosial, matematis serta mampu berpindah antar representasi. Mengadaptasi pembahasan oleh beberapa peneliti (Arcavi, 2003; Haciomeroglu \& Chicken, 2012), jenis representasi dapat dikategorikan sebagai representasi analitis dan representasi visual. Kurikulum dan pendidikan matematika perlu memberikan pandangan yang lebih luas bagi guru dan siswa dalam mengenali bahasa alami dan representasi visual matematika (Lemke, 2002).

Selanjutnya Boonen, Van Wesel, Jolles, \& Van der Schoot (2014) membedakan representasi visual menjadi tiga tipe, yaitu representasi piktorial, representasi visual-skematik tidak akurat, dan representasi visual-skematik akurat. Representasi piktoral hanya berfokus pada penampakan eksternal dari objek atau orang tanpa memperhatikan struktur situasi masalah yang dideskripsikan pada teks. Sedangkan representasi skematik yaitu gambaran yang berelasi dengan solusi masalah, yang dapat dikategorikan sebagai gambaran yang akurat dan tidak akurat berdasarkan relevansinya dengan solusi masalah. Kemampuan representasi matematis siswa dapat dihasilkan dari lingkungan pembelajaran yang disediakan, termasuk media dan pendekatan pembelajaran yang digunakan (Miftah \& Orlando, 2016; Lipovec \& Antolin, 2015)

Mengenai peran representasi visual, Arcavi (2003) menglasifikasi kesulitan dalam visualisasi meliputi kesulitan kultural, kognitif, dan sosiologi. Kesulitan kultural berkaitan dengan kepercayaan mengenai visualisasi mana yang dapat dipercaya atau dapat diterima. Kesulitan kognitif meliputi penalaran dengan konsep dalam visualisiasi kadang-kadang menjadi lebih "beresiko" serta dibutuhkan kemampuan fleksibilitas dan kompetensi translasi antara representasi visual dan analitis dalam situasi yang sama. Sedangkan kesulitan sosiologis berkaitan dengan masalah pedagogik serta latar belakang kultural yang mungkin berbeda antar siswa.

Berdasarkan penyelidikan Umah, As'ari, \& Sulandra (2014), terdapat representasi yang beragam oleh siswa 
dalam memodelkan kejadian dinamis. Representasi tersebut berupa representasi konvensional (grafik bidang kartesius) maupun representasi non-konvensional yang berupa piktorial dan visual-skematik. Dalam penyelidikan muncul kecenderungan level penalaran yang lebih baik pada siswa yang menunjukkan representasi yang akurat daripada siswa yang menunjukkan representasi piktorial berupa atribut fisik dari situasi nyata tanpa memperhatikan struktur internal masalah, contohnya gambaran manusia. Peneliti menduga bahwa siswa yang menunjukkan representasi piktorial lebih banyak dipengaruhi oleh konteks lingkungan yang mengelilingi masalah yang disajikan. Pada sebagian siswa laki-laki, representasi non konvensional visual-skematik yang menjadi jembatan untuk menyatakan koordinasi perubahan nilai dua kuantitas secara simultan, namun hal ini tidak ditemukan pada siswa perempuan di penelitian Umah et al., (2014). Temuan tersebut perlu penyelidikan lebih lanjut mengenai perbedaan respon laki-laki dan perempuan dalam memodelkan kejadian dinamis ke dalam representasi visual.

Berkaitan dengan seberapa besar suatu individu terpengaruh oleh konteks lingkungan yang mengelilinginya, mengacu pada Witkin, Moore, Goodenough, \& Patricia W. Cox. (1977), gaya kognitif individu dapat dikategorikan sebagai field dependent dan field independent. Namun, hal ini ini tidak berarti bahwa hanya ada dua tipe individu yang benar-benar berbeda, pada kenyataannya sangat sedikit individu yang menunjukkan sebagai murni field dependent atau field independent. Gaya kognitif sangat mungkin dapat dibentuk dan bukan sesuatu yang kaku (Zhang \& Sternberg, 2009; Snowman, McCown, \& Biehler, 2012).
Snowman et al. (2012) menyatakan bahwa gaya kognitif field dependent dan field independent mengacu pada jangkauan persepsi dan pemikiran seseorang tentang potongan informasi tertentu yang dipengaruhi oleh konteks yang mengelilinginya. Persepsi seseorang dengan gaya field dependent sangat dipengaruhi oleh lingkungan yang dominan, sedangkan seorang field independent lebih dapat memisahkan informasi yang dituju meskipun informasi tersebut berada dalam konteks yang lebih luas dan kompleks. An \& Carr (2017) menyatakan bahwa pada dasarnya mengukur field dependent/field independent adalah mengukur kemampuan visual spasial.

Menurut Snowman et al. (2012), banyak hasil penelitian menunjukkan perbedaan antara laki-laki dan perempuan dalam hal pencapaian dan fungsi kognitif. Laki-laki cenderung mengungguli perempuan dalam tes visual spasial dan penalaran matematis, sedangkan perempuan mengungguli laki-laki dalam tes memori dan penggunaan bahasa. Namun, juga banyak penelitian yang secara statistik tidak menunjukkan perbedaan performa akademik antara laki-laki dan perempuan. Hasil penelitian Haciomeroglu, Chicken, \& Dixon (2013) menunjukkan tidak ada perbedaan signifikan pada laki-laki dan perempuan dalam hal kemampuan kognitif. Haciomeroglu \& Chicken (2012) juga menyatakan bahwa preferensi visual tidak dipengaruhi oleh gender.

Lingkungan pembelajaran harus dapat mengakomodasi keberagaman karakteristik individu peserta didik. Namun, dugaan tentang pengaruh gaya kognitif dan jenis kelamin terhadap proses visualisasi matematis yang mendukung penalaran serta perbedaan hasil-hasil penelitian terdahulu mendorong kebutuhan untuk penyelidikan 
lebih lanjut dalam karakteristik subjek lakilaki dan perempuan berdasarkan gaya kognitif. Artikel ini bertujuan untuk mendeskripsikan karakteristik representasi visual mahasiswa dalam memodelkan kejadian dinamis ditinjau dari perbedaan gaya kognitif field dependent dan field independent serta berdasarkan perbedaan jenis kelamin.

\section{METODE PENELITIAN}

Untuk menjawab pertanyaan penelitian ini, peneliti perlu memperoleh informasi secara rinci mengenai proses berpikir subjek. Oleh karena itu, penelitian ini menggunakan pendekatan kualitatif dengan metode studi multi kasus (multiple case studies). Ulfatin (2017) mengungkapkan bahwa alasan seorang peneliti memilih studi multi kasus antara lain karena studi ini dapat mengkaji persamaan dan perbedaan antar kasus serta dapat melakukan generalisasi hasil dari beberapa kasus.

Subjek penelitian ini adalah mahasiswa dengan asumsi bahwa mahasiswa sebagai individu peserta didik yang lebih dewasa memiliki kecenderungan gaya belajar yang telah terbentuk karena kecenderungan gaya belajar terbentuk oleh cara seseorang mempersepsikan sesuatu dan cara berpikir yang konsisten sepanjang waktu. Snowman et al. (2012) menegaskan bahwa gaya belajar bukan merupakan model perilaku yang tetap, seseorang mungkin dapat mengadaptasi dan mengubah gaya mereka ketika situasi di sekitarnya mendukung. Subjek penelitian ini yaitu dua mahasiswa laki-laki semester 4 Program Studi Matematika dan dua mahasiswa perempuan semester 4 Pendidikan Matematika Universitas Pesantren Tinggi Darul Ulum Jombang. Subjek dipilih berdasarkan hasil Group
Embedded Figures Test (GEFT) yang mengacu pada instrumen Witkin et al., (1977). Hasil GEFT digunakan sebagai acuan utama untuk mengelompokkan mahasiswa sebagai Field Dependent (FD) dan Field Independent (FI) dengan kriteria seperti pada Tabel 1. Mahasiswa dengan kategori Field Neutral tidak dipilih sebagai subjek untuk menghindari subjek dengan kecenderungan Field Dependent atau Field Independent kurang kuat.

Tabel 1. Kategori Gaya Kognitif Berdasarkan Skor GEFT

\begin{tabular}{cc}
\hline Skor GEFT & Kategori \\
\hline $0-8$ & Field Dependent \\
\hline $9-14$ & Field Neutral \\
\hline $15-18$ & Field Independent \\
\hline Sumber: Oh \& Lim (2005) &
\end{tabular}

Masing-masing kelompok kembali dikategorikan sehingga terbentuk kategori FI laki-laki, FI perempuan, FD laki-laki, $F D$ perempuan. Meskipun secara teori ada pendapat yang menyatakan bahwa individu field independent lebih unggul di bidang matematika atau sains (Snowman et al.; 2012), namun hasil tes GEFT pada penelitian ini tidak menunjukkan hasil yang konsisten antara mahasiswa dengan performa kategori atas dan sedang. Mahasiswa dengan performa kelompok bawah memang menunjukkan kecenderungan field dependent, namun tidak berlaku sebaliknya. Oleh karena itu, untuk memperkecil kemungkinan hasil yang bias, peneliti memilih subjek yang memiliki performa di kelas yang setara namun tidak pada kategori performa rendah agar memperoleh data yang lebih mendalam. Berdasarkan prosedur pemilihan subjek tersebut, diperoleh 4 subjek masingmasing satu subjek untuk tiap kategori seperti yang disajikan pada tabel 2 . 
Tabel 2. Karakteristik Subjek Berdasarkan Gaya Kognitif dan Jenis Kelamin

\begin{tabular}{|c|c|c|}
\hline Subjek & $\begin{array}{c}\text { Jenis } \\
\text { kelamin }\end{array}$ & Gaya Kognitif \\
\hline L-FI & Laki-laki & $\begin{array}{c}\text { Field } \\
\text { Independent }\end{array}$ \\
\hline P-FI & Perempuan & $\begin{array}{c}\text { Field } \\
\text { Independent }\end{array}$ \\
\hline L-FD & Laki-laki & $\begin{array}{c}\text { Field } \\
\text { Dependent }\end{array}$ \\
\hline P-FD & Perempuan & $\begin{array}{c}\text { Field } \\
\text { Dependent }\end{array}$ \\
\hline
\end{tabular}

Data penelitian diperoleh melalui tes dan wawancara. Tes yang diberikan bertujuan untuk menggali informasi mengenai respon tertulis subjek dalam memodelkan suatu kejadian dinamis yang berkaitan dengan koordinasi nilai-nilai dua kuantitas dalam representasi visual. Tes berupa tugas untuk menggambarkan grafik berdasarkan masalah situasi nyata yang diberikan. Tes dan wawancara untuk setiap subjek dilakukan dalam tiga sesi yang dilakukan sekali dalam satu minggu. Masing-masing sesi berlangsung sekitar 60 menit.

\section{HASIL DAN PEMBAHASAN}

Subjek penelitian ini yaitu empat mahasiswa yang terdiri dari dua mahasiswa laki-laki dan dua mahasiswa perempuan di Unipdu Jombang. Data penelitian diperoleh dengan membandingkan respon tertulis dan hasil wawancara subjek field dependent dan field independent dengan jenis kelamin berbeda. Tugas yang diberikan dalam tes pada penelitian ini hanya berkaitan dengan grafik yang menuntut pemrosesan secara visual, namun kemunculan representasi visual sebelum mengonstruk grafik bukan bagian dari tuntutan dalam tes, melainkan sebagai respon alami yang ditunjukkan subjek selama melakukan penalaran.
Berdasarkan perbedaan gaya kognitif field dependent/field independent, tidak ditemukan perbedaan signifikan yang konsisten bagi semua kasus mengenai karakteristik representasi visual dalam memodelkan suatu kejadian dinamis, meskipun terdapat indikasi bahwa subjek field independent memiliki level penalaran yang lebih tinggi. Hal ini sejalan ketika meninjau secara teoritis bahwa pada umumnya efek positif field independent lebih terlihat pada ilmu sains, sedangkan field dependent lebih unggul dalam konteks sosial (Snowman et al., 2012). Witkin et al. (1977) serta Zhang \& Sternberg (2009) juga memberikan catatan bahwa perbedaan gaya kognitif ini tidak menandakan perbedaan kemampuan, melainkan sebagai perbedaan respon terhadap lingkungan dan konten pembelajaran.

Ketika meninjau perbandingan kasus berdasarkan perbedaan jenis kelamin, tidak tampak perbedaan signifikan yang konsisten dari semua kasus antara subjek perempuan dan laki-laki mengenai cara merepresentasikan kejadian dinamis secara visual, namun pada salah satu kasus individu perempuan P-FD paling sering menggunakan atribut grafik secara rinci saat mengonstruk koordinasi antara nilainilai pada kedua variabel seperti pada Gambar 1. Hasil ini sesuai dengan hasil penelitian Haciomeroglu \& Chicken (2012) bahwa preferensi visual tidak dipengaruhi oleh gender. Namun, terkait dengan penggunaan representasi visual nonkonvensional, laki-laki cenderung lebih sering menggunakannya dibandingkan dengan perempuan meskipun tingkat kecanggihannya secara matematis tidak selalu sama dalam membantu penalaran. 


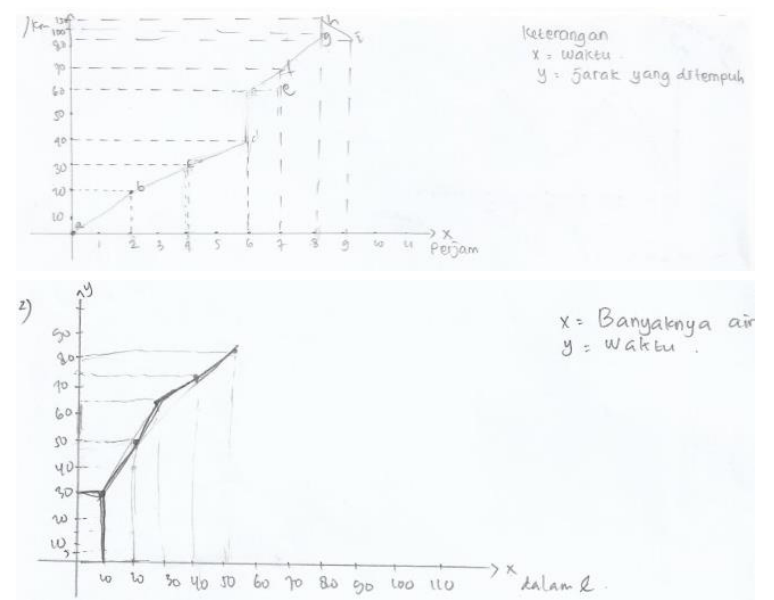

Gambar 1. Grafik oleh P-FD Memiliki Karakteristik Atribut Grafik yang Lebih rinci

Selanjutnya Haciomeroglu et al. (2013) menambahkan bahwa tidak ditemukan perbedaan signifikan antara individu dengan jenis kelamin berbeda dalam hal kemampuan kognitif, preferensi visual/analitis, serta performa kalkulus.

Namun pada penelitian Gallager \& De Lisi (1994) menunjukkan bahwa di antara siswa dengan kemampuan tinggi, terdapat perbedaan yang signifikan di antara laki-laki dan perempuan yaitu lakilaki lebih menggunakan strategi nonkonvensional dan sebaliknya perempuan lebih menggunakan strategi konvensional. Nampaknya perbedaan signifikan pada penelitian Gallager \& De Lisi (1994) dapat terjadi karena subjek penelitian hanya pada siswa berkemampuan tinggi. Sedangkan pada penelitian ini, semua subjek berada pada kemampuan sedang. Gallager \& De Lisi (1994) juga menunjukkan bahwa masalah tidak rutin lebih menguntungkan bagi laki-laki. Pada penelitian ini, masalah yang disajikan merupakan masalah tidak rutin. Boonen et al. (2014) menegaskan kesimpulan bahwa keakuratan representasi visual meningkatakan kesempatan bagi keberhasilan menyelesaikan masalah dalam soal cerita serta Haciomeroglu \& Chicken (2012) menyarankan bahwa preferensi yang lebih kuat dalam berpikir visual berhubungan dengan performa matematika yang lebih tinggi. Sedangkan studi longitudinal oleh Fennema, Carpenter, Jacobs, Franke, \& Levi (1998) menyimpulkan tidak ada perbedaan antar gender dalam hal pemecahan masalah namun strategi yang digunakan cenderung berbeda. Perempuan cenderung menggunakan strategi konkrit, sedangkan laki-laki lebih menggunakan strategi abstrak.

Meskipun tidak ditemukan perbedaan signifikan yang konsisten antara laki-laki dan perempuan, dan antara field dependent dan field independent, namun jika kita mengambil kasus yang dibedakan dari kedua variabel secara bersamaan secara khusus terdapat temuan yang menarik. Perbedaan yang relatif berarti terjadi antara subjek laki-laki field independent (L-FI) dan subjek perempuan field dependent (PFD). Meskipun kedua subjek belum mencapai level penalaran kovariasional tertinggi L-FI cenderung menggunakan strategi visual nonkonvensional dan menunjukkan penalaran yang lebih baik, sedangkan P-FD selalu menggunakan prosedur yang detail dalam mengkonstruk grafik, seperti melakukan penomoran secara lengkap pada kedua sumbu dan membuat garis bantuan putus-putus untuk mengoordinasikan nilai dari kedua sumbu namun kesulitan membidik informasi penting yang "tidak terlihat" dalam soal tes. Gambar 2 menunjukkan perbandingan salah satu respon kedua subjek. 


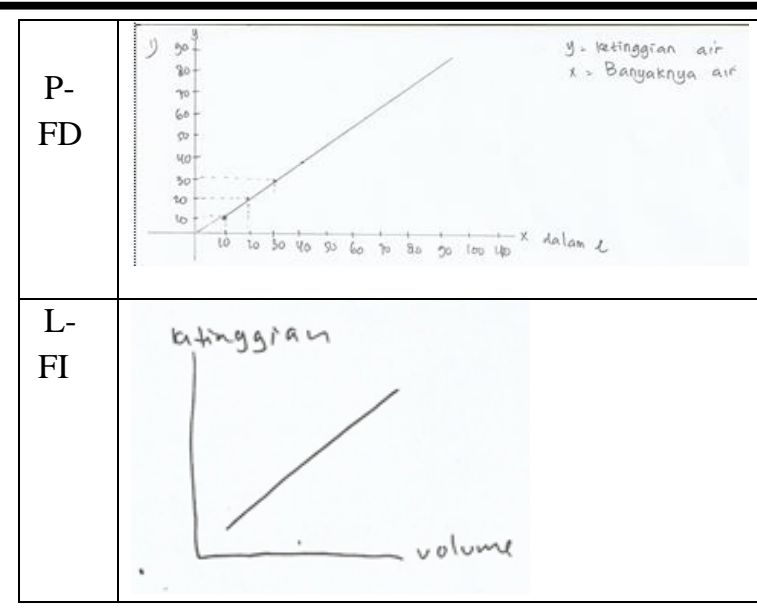

Gambar 2. Perbandingan Karakteristik Grafik oleh L-FI dan P-FD.

Perbedaan antara kedua subjek tersebut diperkuat oleh kesesuaiannya secara teoretis bahwa persepsi seorang field dependent sangat dipengaruhi oleh lingkungan yang meliputinya dan sulit memisahkan informasi yang dituju dan perempuan lebih memiliki kecenderungan kuat untuk menggunakan prosedur rutin dan konvensional, sedangkan field independent dan laki-laki sebaliknya. Mengenai prosedur rutin yang dilakukan P-FD dapat dimungkinkan pengaruh prosedur yang diajarkan dalam lingkungan belajar sebelumnya namun perlu penyelidikan lebih lanjut mengenai hal ini.

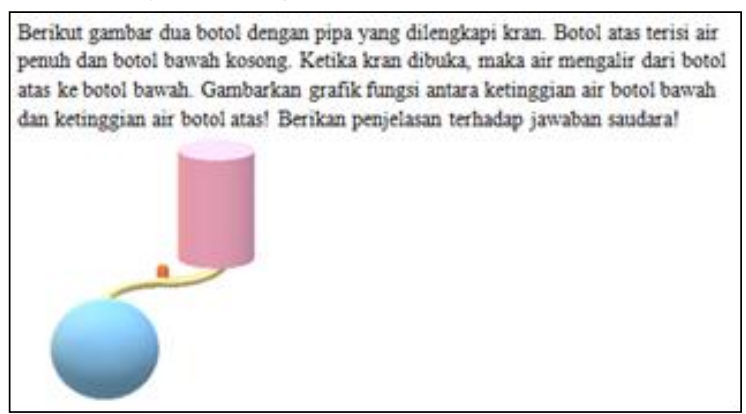

Gambar 3. Salah Satu Masalah yang Disajikan dalam Tes yang Memiliki Tingkat Kerumitan Lebih Tinggi, Diadopsi dari Subanji (2011)

Gambar 4 menunjukkan subjek L-FI ketika menghadapi masalah dengan komplekstitas yang tinggi (masalah pada
Gambar 3), ia membuat abstraksi informasi yang diperlukan serta menyatakannya dalam representasi visual nonkonvensional.

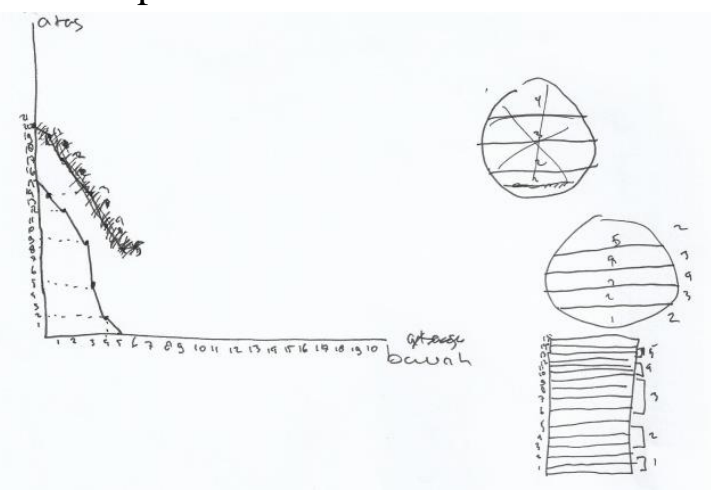

Gambar 4. Respon Visual Subjek L-FI dalam Membangun Penalaran untuk Masalah yang Lebih Kompleks

Subjek L-FI merepresentasikan ketinggian air pada kedua botol dan menyesuaikannya dengan nilai-nilai pada kedua sumbu. Penggunaan representasi visual ini menjadi jembatan dalam proses koordinasi nilai-nilai variabel sebelum disajikan dalam grafik konvensional. Jembatan visualisasi tersebut sebagai upaya subjek untuk memudahkan dalam proses penalaran. Bantuan representasi nonkonvensional seperti di Gambar 4 digunakan oleh subjek dalam koordinasi ketinggian botol atas dan botol bawah dengan waktu yang bersesuaian. Meskipun L-FI tidak menunjukkan perubahan pada setiap titik, namun ia dapat membayangkan perubahan nilai secara kontinu pada selangselang tertentu dan ia membayangkan kedua variabel bervariasi dengan variasi kontinu chunky seperti yang disebutkan (Castillo-Garsow, Johnson, \& Moore, 2013). Peran visualisasi ini didukung temuan Yung \& Paas (2015) bahwa siswa dengan lingkungan belajar yang menyediakan representasi visual memiliki lebih sedikit beban kognitif daripada siswa dengan lingkungan belajar tanpa representasi visual. Mengenai penggunaan 
visualisasi nonkonvensional, David, Tomaz, \& Ferreira (2014) menunjukkan bagaimana visualisasi nonkonvensional berperan dalam prosedur aljabar, namun guru perlu membimbing penggunaan visualisasi ini agar harus selalu dihubungkan dengan makna matematis.

Generalisasi kasus dari hasil penelitian ini terbatas pada pandangan terhadap subjek berdasarkan jenis kelamin dan gaya kognitif FI-FD sehingga ada kemungkinan hasil yang berbeda pada kasus lain dengan karakteristik individu yang lebih lengkap selain yang dideskripsikan pada penelitian ini. Arcavi (2003) menyatakan bahwa salah satu hambatan dalam visualisasi dari sisi sosiologis yaitu perbedaan latar belakang kultural subjek yang mungkin beragam. Oleh karena itu, perlu penyelidikan lebih lanjut dengan menguraikan lebih rinci tentang aspek latar belakang tersebut.

\section{SIMPULAN}

Penelitian ini tidak menemukan perbedaan signifikan yang konsisten dengan membandingkan antara subjek field dependent dan field independent serta antara subjek laki-laki dan subjek perempuan dalam hal karakteristik representasi visual matematis. Namun, perbedaan lebih tampak ketika membandingkan antara subjek laki-laki field independent dan perempuan field dependent. Subjek laki-laki dengan gaya field independent memiliki kecenderungan lebih kuat untuk menggunakan bantuan representasi non-konvensional sebelum menyatakannya dalam representasi yang lebih konvensional berupa grafik, sedangkan subjek perempuan dengan gaya kognitif field dependent lebih prosedural dan menggunakan cara rutin.

Penelitian ini terbatas pada beberapa kasus. Perluasan kasus serta deskripsi latar belakang subjek secara lebih rinci memungkinkan temuan yang lebih luas. Oleh karena itu, peneliti menyarankan adanya penelitian lanjutan dengan menyertakan pandangan berdasarkan perbedaan latar belakang kultural subjek terutama mengenai pengalaman belajar yang diperoleh sebelumnya.

\section{UCAPAN TERIMA KASIH}

Penelitian ini terselenggara dengan dukungan dana dari Direktorat Riset dan Pengabdian Masyarakat, Direktorat Jenderal Penguatan Riset dan Pengembangan, Kementerian Riset, Teknologi, dan Pendidikan Tinggi (Kemenristekdikti) Tahun 2018.

\section{DAFTAR PUSTAKA}

An, D., \& Carr, M. 2017. "Learning Styles Theory Fails to Explain Learning and Achievement: Recommendations for Alternative Approaches". Personality and Individual Differences, Vol. 116, pp: 410-416.

Arcavi, A. 2003. "The Role of Visual Representations in the Learning of Mathematics". Educational Studies in Mathematics. Vol. 52 (3), pp: 215-241.

Boonen, A. J. H., Van Wesel, F., Jolles, J., \& Van der Schoot, M. 2014. "The Role of Visual Representation Type, Spatial Ability, and Reading Comprehension in Word Problem 
Solving: An Item-Level Analysis in Elementary School Children". International Journal of Educational Research. Vol. 68, pp: 15-26.

Carlson, M. P., Jacobs, S., Coe, E., Larsen, S., \& Hsu, E. 2002. "Applying Covariational Reasoning While Modeling Dynamic Events: A Framework and A Study". Journal for Research in Mathematics Education. Vol. 33 (5), pp: 352-378.

Castillo-Garsow, C., Johnson, H. L., \& Moore, K. C. 2013. "Chunky and Smooth Images of Change". For the Learning of Mathematics. Vol. 33 (3), pp: 31-37.

David, M. M., Tomaz, V. S., \& Ferreira, M. C. C. 2014. "How Visual Representations Participate in Algebra Classes' Mathematical Activity". ZDM Mathematics Education. Vol. 46 (1), pp: 95-107.

Fennema, E., Carpenter, T. P., Jacobs, V. R., Franke, M. L., \& Levi, L. W. 1998. "A Longitudinal Study of Gender Differences in Young Children's Mathematical Thinking". Educational Researcher. Vol. 27 (5), pp: 6-11.

Gallager, A. M., \& De Lisi, R. 1994. "Gender Difference in Scholastic Aptitude TestMathematics Problems Solving Among High School Students". Journal for Research in Mathematics Education. Vol. 86 (2), pp: 204-211.

Haciomeroglu, E. S., \& Chicken, E. 2012. "Visual Thinking and Gender Differences in High School Calculus". International Journal of Mathematical Education in Science and Technology. Vol. 43 (3), pp: 303-313.

Haciomeroglu, E. S., Chicken, E., \& Dixon, J. K. 2013. "Relationships Between Gender, Cognitive Ability, Preference, and Calculus Performance". Mathematical Thinking and Learning. Vol. 15 (3), pp: 175-189.

Lemke, J. L. 2002. "Mathematics in The Middle: Measure, Picture, Gesture, Sign, and Word. In M. Anderson, A. Saenz-Ludlow, S. Zellweger, \& V. Cifarelli (Eds.)". Educational Perspectives on Mathematics as Semiosis: From Thinking to Interpreting to Knowing. Ottawa: Legas Publishing, pp: 215-234.

Lipovec, A., \& Antolin, D. 2015. "Schematic and Pictorial Representations of Exponentiation. In O. Fleischmann, R. Seebauer, H. Zoglowek, \& M. Aleksandrovich (Eds.)". The Teaching Profession. LIT Verlag Münster, pp. 137-144.

Miftah, R., \& Orlando, A. R. 2016. "Penggunaan Graphic Organizer dalam Meningkatkan Kemampuan Representasi Matematis Siswa". FIBONACCI: Jurnal Pendidikan Matematika dan Matematika. Vol. 2 2, pp: 72-89.

NCTM. 2002. Principles and standards for school mathematics. Reston V.A: NCTM.

Oh, E., \& Lim, D. 2005. "Cross Relationships Between Cognitive Styles and Learner Variables in Online Learning Environment". Journal of Interactive Online Learning. Vol. 4 (1), pp: 53-66.

Snowman, J., McCown, R., \& Biehler, R. 2012. Social Cognitive Theory. Psychology Applied to Teaching (13th ed.). Belmont, CA: Wadsworth, Cengage Learning.

Subanji. 2011. Teori Berpikir Pseudo Penalaran Kovariasi. Malang: UM Press.

Tall, D. 2009. "Dynamic Mathematics and The Blending of Knowledge Structures in The Calculus". ZDM - The International Journal on Mathematics Education. Vol. 41 (4), pp: $481-492$. 
Thompson, P. W., \& Carlson, M. P. 2017. "Variation, Covariation, and Functions: Foundational Ways of Thinking Mathematically. In J. Cai (Ed.), Compendium for Research in Mathematics Education. Reston, VA: Compendium for research in mathematics education, pp. 421-456.

Ulfatin, N. 2017. Metode Penelitian Kualitatif di Bidang Pendidikan: Teori dan Aplikasinya. Malang: Media Nusa Creative.

Umah, U., As'ari, A. R., \& Sulandra, I. M. 2014. Penalaran Kovariasional Siswa Kelas VIIIB MTS Negeri Kediri 1 dalam Mengkonstruk Grafik Fungsi. Thesis. Malang: Universitas Negeri Malang.

Witkin, H. A., Moore, C. A., Goodenough, D. R., \& Patricia W. Cox. 1977. "Field-Dependent and Field-Independent Cognitive Styles and Their Educational Implications". Review of Educational Research. Vol. 47 (1), pp: 1-64.

Yung, H. I., \& Paas, F. 2015. "Effects of Computer-Based Visual Representation on Mathematics Learning and Cognitive Load". Educational Technology and Society. Vol. 18 (4), pp: 70-77.

Zhang, L.-F., \& Sternberg, R. J. 2009. Perspectives on the nature of intellectual styles. New York: Springer. 